\title{
A review of multispousal relationships - psychosocial effects and therapy
}

\author{
M Y H Moosa, FCPsych \\ R Benjamin, PhD Clinical Psychology \\ F Y Jeenah, MMed Psych \\ Division of Psychiatry, University of the Witwatersrand, \\ Johannesburg
}

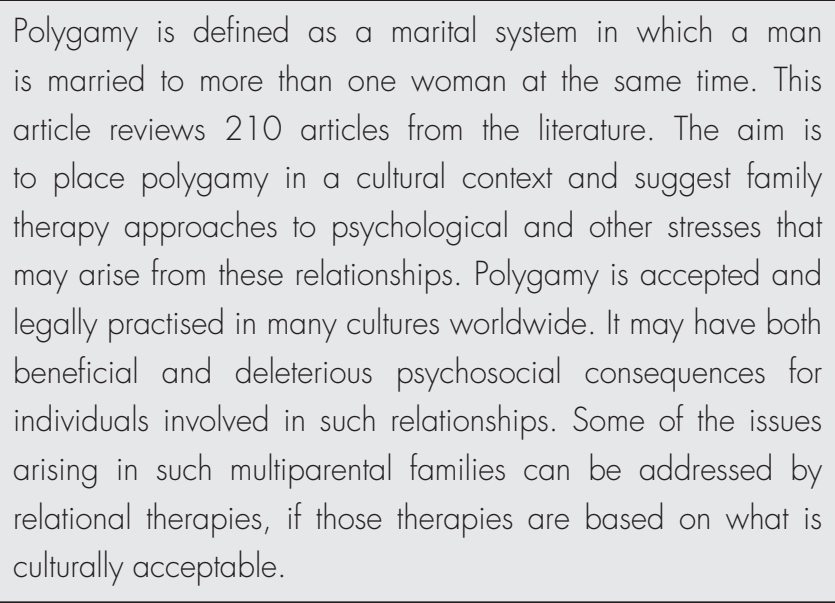

Polygamy is defined as a marital system in which a man is married to more than one woman at the same time. 'This form of multispousal relationship is practised legally in over 850 societies worldwide and is accepted by a wide range of non-Western ethnic and religious groups. In some Western societies polygamy is a criminal offence and the practice thereof has legal implications (S Chapman - unpublished data, IslamVision.org). Women in polygamous marriages lose certain rights that are provided for in monogamous marriages. In South Africa the promulgation of the Customary Marriages Act of November in 2000 resulted in polygamous marriages being officially recognised, with women seen as equal partners having equal rights in such relationships. The purpose of this article was to review some of the existing literature with a view to placing polygamy in a cultural context and to suggesting possible therapeutic approaches to psychological and other stresses within the families that may arise from these relationships.

\section{Religious and cultural views}

Polygamy is a major institution in Middle Eastern and African societies. ${ }^{2}$ Although Judaism banned polygamous marriages, it is still practised by the Jews of Yemen. ${ }^{3}$ The Catholic Church rejected polygamy in the 16th century, ${ }^{4}$ yet some Latter Day Saints and Mormon fundamentalists continue to uphold and engage in such relationships. ${ }^{2}$ In Islamic cultures a man is allowed up to 4 wives on condition that he possesses sufficient financial resources to support all the wives and their children; that there be symmetrical treatment, support, love and attention accorded to each wife and her children; and that there be equal distribution of the family's resources among all the wives and their children. ${ }^{5}$ Most African societies practise polygamy (E K Twesigye - unpublished data). These marriages are according to local custom and have always been legal in the understanding of the local world-view. Traditionally, black South Africans believed that the chain of succeeding generations was ensured and that their ancestors would not die through lack of descendants if a man slaughtered a cow at least once a year, and had at least 3 wives and many children. ${ }^{6}$ In the Xhosa law of Transkei it is a tradition that a man has as many wives as he can afford to marry.?

\section{Psychosocial effects on the family}

\section{Wives}

Women who choose polygamous over monogamous marriages sometimes do so even in the absence of any pressure from family and relatives. ${ }^{8}$ For them the critical relationship is not just with the husband, but with his female associates, including both kin and co-wives.

Polygamy may lead to jealousy, competition, disputes over unequal distribution of household resources and the development of mental ill health in the women involved in the relationships. They may suffer from a wide variety of psychiatric symptoms including higher incidences of somatisation, anxiety symptoms, diminished self-esteem, loneliness and disturbances of memory and appetite than women in monogamous relationships. ${ }^{10}$ The polygamous relationship may contribute to a diminished sense of personal value and potency because a wife has to compete with another woman to 'gain' her husband's heart. Senior wives suffer from significantly more symptoms of somatisation, interpersonal sensitivity, depression, anxiety ${ }^{10}$ and low self-esteem ${ }^{11}$ than their junior counterparts.

Although wife abuse is common in polygamous relationships, ${ }^{12}$ women tend not to report their abuse to the social services for fear of losing their status and children. A woman's social status in a society that practises polygamy is based on her marriage and her ability to have and rear children, especially boys. In such a 
society a good wife and mother is expected not to be absent from her husband's home except for everyday chores, and it is expected that she will sacrifice her own needs for the sake of her family.

\section{Husbands}

In Western society polygamy may be thought to be motivated only by sexual needs. However, in cultures that practise polygamy men are seen as taking on a tremendous responsibility. ${ }^{4}$ They have to manage intimate, special and unique relationships with more than one woman at the same time. They have to reassure all the wives and pay special attention to day-to-day adjustments. They are expected to be wise, all-knowing, calm and always available to help resolve conflicts.?

Having all these responsibilities and working to provide for the family can be extremely stressful. In some instances men leave their senior wives and children in order to live with their later wives and children. In such situations the father may not participate in the upbringing of all of his children and those left behind may experience feelings of grief and abandonment, and in the case of the children, lower levels of parental supervision.

\section{Children}

In communities that practise polygamous marriage children are raised to perceive themselves not as autonomous individuals, but as deeply interdependent with their community. No boundaries exist separating one family (nuclear or extended) from another.

There may be a reduction in the amount of supervision and parental attention received by each child lespecially from the father) and a lack of parental role models because of conflict between and among parents (S Chapman - unpublished data, IslamVision.org). Children may sometimes become the displaced targets of their parents' frustrations and be treated as scapegoats. This may weaken the parent-child bond, thus reducing the child's emotional satisfaction and emotional security.

Children of polygamous marriages exhibit higher levels of envy, conflict, emotional stress, tension, insecurity and anxiety than children of monogamous marriages. ${ }^{13}$ They have a more negative self-concept, perhaps because of increased competition among mixed siblings for an important place in the family. ${ }^{14}$ They can also present with a variety of behavioural problems and belowaverage academic achievement. ${ }^{15}$ It is possible that large families may suffer from limited resources (time, energy, money per child) and these insufficiencies may directly undermine children's achievement in school. The average achievement scores of children from polygynous families are significantly lower than those of children from monogamous families.?,16
However, examination of scholastic achievement differences among adolescents has shown no deleterious effects of polygamy on achievement level. ${ }^{15,17}$ Adolescents usually do not feel themselves to be stigmatised and do not perceive their family structure to be disadvantaged. ${ }^{13,18}$ They tend to be more resourceful and better equipped to adjust to any adverse circumstances.

The values that support the polygamous family are the same as the values within that community at large. ${ }^{13}$ The members tend to have the same patterns of child rearing, providing youths with the same development and opportunities, and ensuring that their approaches to living, thinking, and problem solving are similar. ${ }^{19}$ The youth develop strong social networks with their peers as they grow up (many of the youth's peers will be members of the extended family). ${ }^{13}$ The youth's community of peers overlap with the extended family in terms of behavioural and cultural influences. Differences melt away because they go to the same school and place of worship together, and share the same games and television shows. Therefore the distinction between home and the outside world (community of peers) hardly exists in this community.

\section{Therapy}

\section{Family therapy}

Al-Krenawi ${ }^{18}$ did groundbreaking work in family therapy with multispousal families. He recommends that one must work with each unit of a family system separately, but administer therapy to all units at the same time. At various points the family is brought together so that interrelated issues can be addressed. The focus is on promoting understanding between the co-wives and their husband, possibly through the tactic of stressing the children's difficulties. The husband is encouraged to take more interest in the needs and welfare of his wives and children; and through the children, the husband and his wives begin to communicate. In practical terms this means working towards better relationships between the co-wives and their husband, establishing good relationships between the children of the different wives, and building a coalition between the co-wives, including the youngest wife.

\section{Cognitive therapy}

Cognitive distortions often prevail in these relationships, resulting in conflict between the partners. These negative assumptions include all-or-nothing thinking, overgeneralisation, jumping to conclusions, magnification or minimisation, making 'should' statements, labelling and mislabelling, and personalisation and blame. ${ }^{20}$ 
The distorted belief 'that a man is not capable of loving more than one woman at a time' poses a problem when a married man marries another woman. The belief is that all of the man's love will now be concentrated on the new wife with a resultant complete loss of love and a reduction of support for the other wife. This belief is very basic and stems from preverbal times when the newborn child in the family displaces the older sibling. These cognitive distortions may cloud and confuse the individuals in the relationship and may need to be resolved first.

In the context of polygamous relationships, brief cognitive therapy uses the framework of understanding the thought processes of each of the members of the relationship. It combines a solutionfocused approach with the cognitive model. With each session the cognitive distortions and negative assumptions are identified and challenged with each member and the family collectively. Such therapy further attempts to teach all individuals the various techniques for applying the framework to their own case with a view to arriving at solutions. ${ }^{21}$

\section{Multiple dyadic relationships}

Another approach is through achieving multiple dyadic relationships between a husband and wife in plural families. Husbands should be fair, and should honour and love all wives. ${ }^{4}$ The uniqueness and individuality of each wife has to be established. She has to have her own place, own job and own routine. There should be flexibility but at the same time equality. The Islamic precept that all wives have to be treated equally in love, attention and finances provides a key as to how to make this extended family happy and content. ${ }^{5}$ It is important, regardless of whether they all share a house or not, to see the whole as a family and not as a whole lot of families. Brothers and sisters are truly brothers and sisters with loyally to one another just as the wives must have loyalty to one another.

Strategies on how to improve communication, anger management and basic assertiveness techniques are useful and need to be taught. An effective self-esteem builder is an atmosphere of respect and love in the home. This atmosphere is conducive to allowing members of the family to flourish and be 'themselves'. When a person feels loved and secure in any relationship, all their natural good attributes flourish. Every member of the household will need guidance on how to develop the correct atmosphere. Channels of communication have to be opened so that the people involved can be honest and genuine with one another. Spouses should make ongoing effort to build up communication and to set aside time to really 'talk'.

\section{Conclusion}

In African countries polygamy is a reality and therapists are often called on to do marital therapy. Polygamy is not inevitably destined to disappear under the pressures of urbanisation and wage employment. It has both beneficial and deleterious effects on all the individuals involved in the relationship. It is also evident that therapy with a multiparental family can take place, but that it should be based on what is culturally acceptable for that family. The therapist must be aware, sensitive and respectful of these African traditional concepts, and work within these concepts. Western-style strategies may fail because cultural expectations and taboos forbid normal Western techniques, such as confrontational group therapy between the genders in face-to-face sessions. Further studies are required to explore this culturally sensitive problem, as well as studies on the value of any intervention techniques and strategies that take these cultural issues into consideration.

\section{References}

1. Elbedour S, Bart WM, Hektner JM. Scholastic achievement and family marital structure: Bedouin-Arab adolescents from monogamous and polygamous families in Israel. I Soc Psychol 2000; 40: 503-514.

2. Elbedour S, Onwuegbuzie AJ, Caridine C, et al. The effect of polygamous marital structure on behavioral, emotional, and academic adjustment in children: A comprehensive review of the literature. Clinical Child and Family Psychology Review 2002; 5: 255-271.

3. Costanzo J. Polygamy here to stay. http://www.desernnews.com (last accessed 5 May 2006).

4. Altman I, Ginat J. Polygamous Families in Contemporary Society. New York: Cambridge University Press, 1996: 512

5. Al-Krenawi A, Graham JR, Slonim-Nevo V. Mental health aspects of Arab-lsraeli adolescents from polygamous versus monogamous families. J Soc Psychol 2002; 142: 446-460.

6. Mutwa VC. Indaba, My Children. Johannesburg: Blue Crane Books, 1995: 562

7. Cherian VI. Academic achievement of children from monogamous and polygynous families. J Soc Psychol 1990; 130: 117-119.

8. Anderson CM, Hartwick C, Oneonta NY. The persistence of polygyny as an adaptive response to poverty and oppression in apartheid South Africa. Cross-Cultural Research. Journal of Comparative Social Science 2000; 34: 99-1 12.

9. Chaleby K. Traditional Arabian marriages and mental health in a group of outpatient Saudis. Acta Psychiatr Scand 1988; 77: 139-142.

10. Al-Krenawi A, Ben Gurion U. Women from polygamous and monogamous marriages in an outpatient psychiatric clinic. Transcultural Psychiatry 2001 ; 38: 187-199.

11. Al-Krenawi A, Graham J, Izzeldin A. The psychosocial impact of polygamous marriages on Palestinian women. Women Health 2001; 34: 1-16.

12. Al-Krenawi A, Lev-Wiesel R. Wife abuse among polygamous and monogamous Bedouin-Arab families. Journal of Divorce and Remarriage 2002; 36: 151-165

13. Elbedour S, Bart WM, Hektner J. Intelligence and family marital structure: The case of adolescents from monogamous and polygamous families among Bedouin Arabs in Israel. J adolescents from monogamous and
Soc Psychol 2003; 143: 95-1 10 .

14. Owuamanam DO. Adolescents' perception of polygamous family and its relationship to selfconcept. International Journal of Psychology 1984; 19: 593-598

15. Al-Krenawi A, Graham JR, Al-Krenawi S. Social work practice with polygamous families. Child and Adolescent Social Work Journal 1997; 14: $445-458$

16. Al-Krenawi A, Lightman ES. Learning achievement, social adjustment, and family conflict among Bedouin-Arab children from polygamous and monogamous families. J Soc Psycho among Bedouin-Arab ch

17. Elbedour S, Onwuegbuzie AJ, Alatamin M. Behavioral problems and scholastic adjustment among Bedouin-Arab children from polygamous and monogamous marital family structures: some developmental considerations. Genet Soc Gen Psychol Monogr 2003; 129: 213 237

18. Al-Krenawi A. Family therapy with a multiparental/multispousal family. Fam Process 1998; 37: $65-81$.

19. Elbedour S, Hektner JM, Morad M, Abu-Bader SH. Parent-adolescent conflict and its resolution in monogamous and polygamous Bedouin Arab families in southern Israel. Scientific World Journal 2003; 3: 1249-1264

20. Cherian VI. Corporal punishment and academic achievement of Xhosa children from polygynous and monogamous families. I Soc Psychol 1994; 134: 387-389.

21. Baltimore ML. Brief cognitive couple therapy: Thoughtful solutions. In: Watts RE, Carlson J eds. Techniques in Marriage and Family Counselling. Vol. 2. The Family Psychology and
Counselling Series. Alexandria, VA: American Counselling Association, 2002: 49-55. 